current, pressure and radial position in the oxygen discharge are given in Fig. 3. It will be noticed that the conventional picture of the electronegative discharge, in which the negative ions congregate in the centre, where they build up in concentration until equilibrium is established by destruction in the gas phase, tends to be confirmed; although the density of $\mathrm{O}^{-}$at the edge of the discharge suggests that wall loss may prove to be an important contribution to the equilibrium.

A somewhat smaller multistage analyser is now being built for studying in more detail both the concentration and energy distribution of the negative ions, in certain electronegative discharges, with the view of elucidating the processes involved in the equilibrium.

'Spencer-Smith, J. L., Phil. Mag., 19, 1016 (1935).

2 Lunt and Gregg, Trans. Faraday Soc., 234, 1062 (1940).

\section{SAFE MILK IN GREAT BRITAIN}

IN Great Britain neither the milk industry nor government departments concerned with it have, at least during the past two or three decades, suffered from lack of advice. On the contrary, recommendations must have showered on them from many individuals and organisations, some of whom can have had no more than a one-sided acquaintance with the farming, scientific and technological, and economic problems of this extremely complex and varied industry. Proposals made, for example, that bovine tuberculosis should be eliminated forthwith by the overnight slaughter of all reactors to the tuberculin test, or that from to-morrow no milk other than pasteurized should be consumed in Great Britain, merely indicate a lack of understanding of the dimensions of one of the most important of these problems.

Fortunately, both the industry and the govern. ment departments have developed, at least of recent years, a fairly keen sense of discrimination as between wise and constructive suggestions and those which are less good. Incautious or unrealistic government action may have serious repercussions not only on the 250,000 or so families-say, roughly a million people including dependants--whose breadwinners are engaged in milk production or distribution or in one of the several ancillary industries, but also on almost the whole of the population as milk consumers. Progress on the whole has, therefore, been a little slow, though even so some unfortunate legislative errors have been made-such, for example, as the introduction of the 'accredited' scheme without making any provision for uniformity of its adminis. tration throughout the country.

A joint Committee of the British Medical, and the National Veterinary Medical, Associations was set up by those Associations in October 1948 "to consider and report and formulate representations for transmission to government departments on the problem of providing safe milk of high quality for the community and the supervision of production and distribution of other foods of animal origin". This Committee decided at its first meeting that the most important problem to be discussed was milk, and a memorandum recently published* is an interim

- British Medical Association and National Veterinary Medical Association. The Provision of Safe Milk of High Quality. Pp. 8 . (London: British Medical Association, 1949.) report which, it seems, is to be supplemented in a final report to be published later.

Even as an interim report, this memorandum puts forward recommendations which bear the stamp of careful consideration, show evidence of notable acquaintance with the industry, are, for the most part, sane and reasonable, and must clearly be taken into account by the appropriate government departments. The document is on the whole well written, does not waste words and is too full of facts to summarize in a relatively short space.

While the report was in preparation, the Milk (Special Designations) Act 1949 , with the relevant Regulations regarding raw milk and also pasteurized and sterilized milk, became law. It is of interest that the Committee is in full agreement with the general intentions of the Act, but hopes that the Minister will lose no time in promoting orders by which only designated T.T. or pasteurized milk will be sold in specified areas. Few would disagree with this aspiration.

It is, however, difficult to understand why the Committee dislikes the term 'sterilized milk' and would like to see it abolished. In making this recommendation it would appear that all the facts of the case cannot have been before the Committee. There are one or two other statements in the report which would suggest that exact knowledge on a number of less well-known seientific and technical points would have helped the Committee.

In general, it may be said that in most of its recommendations the Committee is on very sound ground. Its main proposals are ahead, though not inordinately so, of existing legislation and practice in Great Britain, and point the way towards future, and it is to be hoped, not too far distant, revision and improvement.

H. D. KAY

\section{MEDICAL USE OF RADIOACTIVE ISOTOPES}

$T$ HE Ludwig Kast Lecture, which inaugurated the Graduate Fortnight for 1949 of the New York Academy of Medicine, was given by Dr. J. R. Lawrence, director of the Donner Laboratory of the University of California, who chose as the subject of his address the use of isotopes for the study and diagnosis of disease. Dr. Lawrence said that up to the present time radioactive isotopes of more than fifty elements have been used for various studies in experimental medicine, and experience has shown that no deleterious effects follow if the whole human body is given less than a tenth of a roentgen of irradiation per twenty-four hours. Usually far less than this is needed for experimental work.

Discussing iron-59 first, he explained that this has been made by bombarding cobalt-58 with deuterons. Iron is very important in the human body ; but the total amount of it present is not much more than $3 \mathrm{gm}$., the iron being intimately bound up with hæmoglobin. Iron-59 emits both beta- and gammarays, so that it can be used not only for measuring the metabolism of iron by taking blood, urine, stools and tissues and measuring the iron directly, but also for studying its turnover and uptake in the living person, because gamma-rays can be detected when counters are placed over various parts of the body. Dr. Huff and Dr. Lawrence standardized the measurement of the rate of utilization of iron in normal 